\title{
HOMESCHOOLING: UMA ABORDAGEM CONSTITUCIONAL E SUA APLICAÇÃO NA ORDEM JURÍDICA BRASILEIRA
}

\author{
Hugo De Pellegrin Coan ${ }^{1}$ \\ Natalia Alberton Dorigon ${ }^{2}$
}

RESUMO: O presente estudo trata sobre o direito à educação de crianças e adolescentes e a possibilidade de que a família lhes preste diretamente a educação formal, mesmo que esta constitua um dever do Estado. O objetivo do trabalho é ajudar na discussão, com observância dos argumentos contrários e favoráveis ao instituto, com um exame acerca do papel da escola e da autonomia familiar, buscando uma ponderação de interesses entre os argumentos contrários e favoráveis ao homeschooling. Para tanto, utilizou-se o método dedutivo e uma abordagem qualitativa e técnicas de pesquisa documental-legal.

Palavras-chave: Educação; Autonomia Familiar; Limites do Estado; Escola; Ponderação de Interesses.

\section{HOMESCHOOLING: A CONSTITUTIONAL APPROACH AND ITS APPLICATION IN THE BRAZILIAN LEGAL ORDER}

\begin{abstract}
The present study deals with the right to education of children and adolescents and the possibility that the family directly provides them with formal education, even if it is a duty of the State. The aim of this work is to help in the discussion, with observance of opposing arguments and favorable to the institute, with an examination of the role of school and family autonomy, seeking a balance of interests between opposing arguments and favorable to homeschooling. For that, we used the deductive method and a qualitative approach and documental-legal research techniques.
\end{abstract}

Keywords: Education; Family Autonomy; State Boundaries; School; Interests.

\footnotetext{
${ }^{1}$ Técnico Judiciário no Tribunal da Justiça de Santa Catarina. Mestrando do Programa de Pós-Graduação em Direito da Universidade do Extremo Sul Catarinense (UNESC), Área de Concentração: Direitos Humanos e Sociedade. Linha de Pesquisa: Direito, Sociedade e Estado. Possuí interesse nas áreas de Direito Constitucional, colisão de princípios, crise institucional e neoconstitucionalismo. Endereço: Rua João Damiani, 215, Centro, Urussanga/SC, CEP: 88840-000. E-mail: hugocoan @ hotmail.com

${ }^{2}$ Advogada regularmente inscrita na OAB/SC sob o $\mathrm{n}^{\circ} 40.772$. Mestranda do Programa de Pós-Graduação em Direito da Universidade do Extremo Sul Catarinense (UNESC), Área de Concentração: Direitos Humanos e Sociedade. Linha de Pesquisa: Direito, Sociedade e Estado. Possuí interesse nas áreas de Direito Constitucional, Direitos Sociais como educação e inclusão social. Endereço: Rua Vereador Roberto Volpato, n. 173, Centro, Orleans/SC, CEP: 88.870-000. E-mail: natydorigon@ hotmail.com
} 


\section{INTRODUÇÃO}

O direito à educação é uma das pedras angulares de uma democracia que preza por oportunizar aos seus cidadãos o direito de emancipação pessoal, profissional e cultural e como vários outros institutos - passa por uma reavaliação no atual momento brasileiro.

A educação vem sendo discutida, no Brasil, em muitos aspectos pelo desmonte do Estado de Bem-Estar Social, seja recente reforma da grade curricular do ensino médio ou com alguns defendendo o famigerado voucher escolar gerando uma verdadeira mercantilização do sistema educacional.

Entretanto, o que se buscará nesse artigo é tratar da autonomia da família e da eventual possibilidade de que essa preste diretamente a educação formal, mesmo que esta constitua um dever do Estado.

O homeschooling teve sua repercussão geral reconhecida no Recurso Extraordinário n. 888.815, julgado em data de 12/09/2018, pelo Supremo Tribunal Federal que, diante da ausência de previsão legal, decidiu pela frequência escolar obrigatória, contudo referida prática não foi declarada inconstitucional, abrindo possibilidade para sua eventual regulamentação (BRASIL, 2018).

Diante da continuidade do debate que não se encerrou com a decisão da Suprema Corte, artigo abordará os institutos direito à educação, da escola, da autonomia familiar e a ponderação de interesses entre os argumentos contrários e favoráveis ao homeschooling.

Pretende-se aqui uma abordagem constitucional e pluralista, observando os argumentos das duas correntes de opinião, a fim de contribuir para o debate acerca do tema.

A metodologia utilizada no trabalho é bibliográfica, com base na leitura e análise de publicações: livros, dissertações, legislação, julgados, dados oficiais de base governamental e documentos jurídicos internacionais. A abordagem da pesquisa é qualitativa, e método dedutivo.

\section{O DIREITO À EDUCAÇÃO}

A educação é um direito humano fundamental intimamente relacionado com a emancipação do indivíduo e pelas oportunidades que surgirão em sua vida. A educação possui forte incidência sobre o futuro profissional, grau de cultura, relações sociais e sobre a capacidade de análise e crítica e sobre tudo de empoderamento. 
Nesse contexto, a Declaração dos Direitos do Homem e do Cidadão de 1948 fez constar em seu art. 26 a universalidade do direito à educação, a saber:

\begin{abstract}
Artigo 26
Toda a pessoa tem direito à educação. A educação deve ser gratuita, pelo menos a correspondente ao ensino elementar fundamental. O ensino elementar é obrigatório. $\mathrm{O}$ ensino técnico e profissional deve ser generalizado; o acesso aos estudos superiores deve estar aberto a todos em plena igualdade, em função do seu mérito. A educação deve visar à plena expansão da personalidade humana e ao reforço dos direitos do homem e das liberdades fundamentais e deve favorecer a compreensão, a tolerância e a amizade entre todas as nações e todos os grupos raciais ou religiosos, bem como o desenvolvimento das atividades das Nações Unidas para a manutenção da paz.

Os pais têm um direito preferencial para escolher o tipo de educação que será dada aos seus filhos.
\end{abstract}

A educação enquanto direito fundamental nas palavras de Nardejane Martins Cardoso (2016, p. 18) "traz a ideia de mínimo necessário em garantia do pleno desenvolvimento das pessoas e das sociedades, assim como se associa à manutenção da dignidade humana e ao progresso social, no sentido de melhorar as condições de vida".

Nessa mesma orientação, a Convenção sobre os Direitos das Crianças de 20 de novembro de 1989 (vigente no Brasil por força do Decreto n 99.710 de 21 de novembro de 1990) estabelece em seu artigo 28 que:

\footnotetext{
Artigo 28

1. Os Estados Partes reconhecem o direito da criança à educação e, a fim de que ela possa exercer progressivamente e em igualdade de condições esse direito, deverão especialmente:

a) tornar o ensino primário obrigatório e disponível gratuitamente para todos;

b) estimular o desenvolvimento do ensino secundário em suas diferentes formas, inclusive o ensino geral e profissionalizante, tornando-o disponível e acessível a todas as crianças, e adotar medidas apropriadas tais como a implantação do ensino gratuito e a concessão de assistência financeira em caso de necessidade;

c) tornar o ensino superior acessível a todos com base na capacidade e por todos os meios adequados;

d) tornar a informação e a orientação educacionais e profissionais disponíveis e accessíveis a todas as crianças;

e) adotar medidas para estimular a frequência regular às escolas e a redução do índice de evasão escolar.
}

A educação, conforme disposto nos artigos $6^{\circ}$ e 205 da Constituição da República Federativa do Brasil, é um direito de todos (BRASIL, 1988). A Declaração de Salamanca proclama que a educação é um direito fundamental da criança, devendo ser oportunizado um nível aceitável de aprendizagem (UNESCO, 1994). 
Esse nível aceitável de aprendizagem pode estar ligado a longevidade da formação, mas também ao nível de conhecimento que o aluno consegue obter. E sobre esse segundo aspecto, é um tanto complexo entender qual é esse nível aceitável de aprendizagem na realidade brasileira, pois diante da multiculturalidade e diversas interfaces do sistema educacional muitos podem ser os pressupostos para se alcançar o nível aceitável de aprendizagem.

Entretanto entende-se que um dos fatores primordiais para alcançar o nível aceitável de aprendizagem é a capacidade de ensinar. Sim, capacidade, pois ensinar é uma arte e segundo o patrono da educação brasileira Paulo Freire (2015, p. 47) "saber ensinar não é transferir conhecimento, mas criar as possibilidades para a sua própria produção ou a sua construção".

O art. 205 da Constituição da República Federativa do Brasil preceitua que a educação é dever do Estado e da família e que será promovida e incentivada com a colaboração da sociedade, objetivando o pleno desenvolvimento da pessoa, seu preparo para o exercício da cidadania e sua qualificação para o trabalho (BRASIL, 1988).

A Lei 8.069, de 13 de julho de 1990 (Estatuto da Criança e do Adolescente), no art. $4^{\mathrm{o}}$, estabelece que é dever da família, da comunidade, da sociedade em geral e do poder público assegurar, com absoluta prioridade, a efetivação dos direitos, dentre eles, à educação, o art. 53 do mesmo estatuto legal assim dispõe: "a criança e o adolescente têm direito à educação, visando ao pleno desenvolvimento de sua pessoa, preparo para o exercício da cidadania e qualificação para o trabalho" (BRASIL, 1990).

Sobre o tema, Nardejane Martins Cardoso em relevante dissertação intitulada “ $O$ Direito De Optar Pela Educação Domiciliar No Brasil” expõe o seguinte:

\begin{abstract}
Assim sendo, ao ser feita leitura da legislação tem-se a relevância da educação expressa no caput do art. 53 do ECA/90, no qual se afirma que toda criança e adolescente têm o direito à educação, com o escopo de angariar pleno desenvolvimento pessoal, cidadania e capacitação profissional e laboral. Além disso, o parágrafo único do mesmo dispositivo dispõe que são direitos dos pais ou responsáveis a ciência do processo pedagógico e a participação das propostas educacionais (2016, p. 16-17).
\end{abstract}

No Brasil, conforme previsão constitucional, a União, os Estados-Membros, o Distrito Federal e os Municípios devem atuar em conjunto na organização e implementação das políticas públicas de educação. 


\section{HOMESCHOOLING: UMA ABORDAGEM CONSTITUCIONAL E SUA APLICAÇÃO NA ORDEM JURÍDICA BRASILEIRA}

É dever do Estado, segundo o artigo 54 da Lei 8.069/1990, assegurar à criança e ao adolescente o ensino fundamental e médio, obrigatório e gratuito, atendimento educacional especializado às pessoas com deficiência, atendimento em creche e pré-escola às crianças de zero a cinco anos de idade, acesso aos níveis mais elevados do ensino, da pesquisa e da criação artística, oferta de ensino noturno regular, adequado às condições do adolescente trabalhador e atendimento no ensino fundamental, através de programas suplementares de material didático-escolar, transporte, alimentação e assistência à saúde (BRASIL, 1990).

O artigo 11 da Constituição da República Federativa do Brasil de 1988 preconiza que os entes federativos devem agir em regime de colaboração a fim de alcançar a universalização do ensino obrigatório (BRASIL, 1988). Em relação aos Estados, a ação consiste prioritariamente nos ensinos fundamental e médio e, em relação aos Municípios, cabe à competência no ensino infantil e no ensino fundamental (BRASIL, 1988).

Em relação à responsabilidade da família destaca-se que a Convenção Sobre os Direitos da Criança, no artigo 18, estabelece que "Caberá aos pais ou, quando for o caso, aos representantes legais, a responsabilidade primordial pela educação e pelo desenvolvimento da criança. Sua preocupação fundamental visará ao interesse maior da criança” (BRASIL, 1990). Os deveres dos pais em relação à educação das crianças e adolescentes também são previstos pela Constituição Federal, pelo Estatuto da Criança e do Adolescente e também pelo Código Civil.

Conforme afirmam Janaína Machado Sturza e Marizélia Peglow da Rosa (2009, p. 116) “a educação é a política pública mais eficaz para construção e para o efetivo exercício da cidadania, bem como para a formação para o trabalho, ambos essenciais para um Estado que se diz Democrático de Direito".

É durante os anos de desenvolvimento humano, ou seja, no período educacional básico que se constrói os valores morais e éticos. A educação é responsável por propiciar ao homem a participação, além de oferecer ferramentas para entender e reconhecer a necessária transformação das condições de vida (ROSA; STURZA, 2009, p. 116).

Por meio da educação é possível conscientizar as pessoas sobre a importância da igualdade de oportunidades, gerando transformações. A construção para uma sociedade mais digna possui ligação direta com a educação (PAULA, 2008, p. 32).

Não restam dúvidas de que a educação desempenha um papel fundamental na vida de todo ser humano, por isso deve ser viabilizada a todos como indispensável política pública 
para a conscientização e aprimoramento destas e para o desenvolvimento da sociedade (MATTOS NETO, 2012).

Posto isto passamos no próximo momento a discorrer sobre o dever do Estado em promover as condições necessárias para educação de crianças e adolescentes.

\section{A ESCOLARIZAÇÃO E SUAS INTERFACES E O DEVER DO ESTADO}

No que se refere às funções estatais, o art. 208, da Constituição Federal de 1988 delineia os meios pelos quais o Estado deverá efetivar o direito à educação. No inciso I, afirma que a educação básica é obrigatória no período dos 04 (quatro) aos 17 (dezessete) anos de idade (BRASIL, 1988). Abarca, portanto, ensino infantil, fundamental e médio.

Segundo o $\S 1^{\circ}$ do art. $208, \mathrm{CF} / 88$, é direito público subjetivo o acesso ao ensino obrigatório, e o $\S 2^{\circ}$ ressalta a responsabilidade das autoridades competentes, seguido pelo $\S 3^{\circ}$ que aponta a competência do poder público para "zelar" pela frequência escolar (BRASIL, 1988).

José Afonso da Silva explica a educação na Ordem Constitucional Brasileira:

\footnotetext{
A educação como processo de reconstrução da experiência é um atributo da pessoa humana, e, por isso, tem que ser comum a todos. É essa a concepção que a Constituição agasalha nos arts. 205 a 214, quando declara que ela é um direito de todos e dever do Estado.

Tal concepção importa, como já assinalamos, em elevar a educação à categoria de serviço público essencial que ao Poder Público impende possibilitar a todos, daí a preferência constitucional pelo ensino público, pelo que a iniciativa privada, nesse campo, embora livre, é, no entanto, meramente secundária e condicionada (arts. 209 e 213) (grifos no original).
}

Ainda no tocante ao papel do Estado é importante recordar que o inciso XXIV do art. 22 da CF/88 estabelece ser de competência exclusiva da União, no contexto federativo, a regulamentação das diretrizes e bases da educação e competência comum aos entes da federação, tem-se o acesso à educação (art. 23, inciso V, da CF/88). Há, ainda, art. 24, inciso IX, da CF/88, previsão da competência concorrente entre União, Estados e Distrito Federal para legislar sobre educação (BRASIL, 1988).

Dentro desse contexto, surge até mesmo a discussão se o ente federativo independente da União - poderia regulamentar o homeschooling em sua área territorial, o que parece ser uma perspectiva interessante, a fim de que estados funcionem como laboratórios dessa prática, porém tal tema será tratado em artigo futuro. 


\section{HOMESCHOOLING: UMA ABORDAGEM CONSTITUCIONAL E SUA APLICAÇÃO NA ORDEM JURÍDICA BRASILEIRA}

Desse modo, a regulamentação brasileira sobre a educação formal é destinada como obrigação do Estado e no sistema escolar.

No mais, acerca da concepção de escola, necessário destacar que é local de acolhida da diversidade humana, cultural e social, por isso é considerada um local privilegiado para se trabalhar questões que envolvem discriminação e preconceito e implementar uma educação voltada à solidariedade, em síntese um lugar de encontro dos diferentes.

O processo de escolarização desempenha papel fundamental no desenvolvimento de crianças e adolescentes, principalmente em relação à socialização. Segundo Farias (2018, p. 273) “o convívio escolar propicia não apenas educação formal, mas também talvez até sobretudo - habilidades fundamentais relacionadas à socialização, à formação de laços de amizade, ao desenvolvimento psíquico, à convivência com a diferença, etc.”.

Em relação à socialização de crianças e adolescentes, a escola é sem dúvida um lugar privilegiado. Há nas escolas a diversidade humana, cultural e social. É um ambiente propício inclusive para educar em Direitos Humanos, abarcando questões relativas à discriminação, preconceito, respeito, solidariedade e entre outros assuntos relevantes à construção de uma sociedade mais justa e solidária.

Sobre a educação em Direitos Humanos destaca-se que já está previsto na Lei de Diretrizes e Bases da Educação Nacional - Lei 9.394/1996 (artigo 26, §9º) a inclusão de conteúdos relativos aos Direitos Humanos nos currículos escolares (BRASIL, 1996).

E, nesse sentido, afim de atingir uma educação para todos a Declaração de Salamanca esclarece que "as escolas regulares [...] constituem os meios mais capazes para combater as atitudes discriminatórias, criando comunidades abertas e solidárias, construindo uma sociedade inclusiva e atingindo a educação para todos” (UNESCO, 1994).

A importância da socialização principalmente nas fases de desenvolvimento de crianças e adolescentes é substancial ainda mais porque nossa sociedade está cada vez mais individualizada e como afirmam Raitz e Zluhan (2014, p. 40) "Uma pessoa só pode reconhecer seus próprios direitos a partir do momento em que consegue perceber os direitos dos outros".

Por outro lado, não podemos ignorar que o Poder Público tem deixado a desejar em relação à educação, pois muitas são as falhas que assombram o sistema educacional no Brasil, como: escolas em condições inapropriadas; professores(as) despreparados(as) e desmotivados(as); materiais pedagógicos defasados, entre outros. 
De acordo com o portal eletrônico do Instituto Nacional de Estudos e Pesquisas Educacionais - Inep ${ }^{3}$, o Programa Internacional de Avaliação de Estudantes - PISA ${ }^{4}$, tradução de Programme for International Student Assessment, avaliou cerca de 13 mil estudantes de 2 a 30 de maio de 2018 e o foco da avaliação neste ano é a leitura, pela qual se busca analisar o conhecimento dos estudantes tendo como base a diversidade de um mundo globalizado, incluindo as habilidades de leitura necessárias, na atualidade, para crescimento individual, sucesso educacional, participação econômica e cidadania. A disponibilização dos resultados da avaliação está prevista para o segundo semestre de 2019.

De acordo com os resultado da última avaliação do PISA, realizada em 2015 com aproximadamente 32 mil alunos em 964 escolas, os resultados do Brasil não foram dos mais favoráveis, comparados aos países da Organização para a Cooperação e Desenvolvimento Económico (OCDE), conforme se extrai-se do site do relatório da própria organização, disponível no site do Instituto Nacional de Estudos e Pesquisas Educacionais Anísio Teixeira:

O desempenho dos alunos no Brasil está abaixo da média dos alunos em países da OCDE em ciências (401 pontos, comparados à média de 493 pontos), em leitura (407 pontos, comparados à média de 493 points) e em matemática (377 pontos, comparados à média de 490 pontos).

Ademais, não custa ressaltar que o atual cenário da educação brasileira com a Emenda Constitucional n. 95/2016, popularmente conhecida como PEC do teto dos gatos, poderá se agravar ainda mais, a conferir ao longo do tempo.

Entretanto o Estado não pode ser o único responsabilizado pelas deficiências da educação escolar, pois algumas famílias também possuem sua parcela de culpa.

E, em relação a isso Nardejane Martins Cardoso (2016, p. 97) afirma em sua dissertação que:

Há um excesso de funções às escolas e um esvaziamento dos deveres da família e da comunidade, que se afastam do dever de garantir os direitos fundamentais dos

\footnotetext{
${ }^{3}$ http://portal.inep.gov.br/pisa.

${ }^{4}$ Avaliação comparada aplicada de forma amostral a estudantes na faixa etária dos 15 anos, idade em que se pressupõe o término da escolaridade básica obrigatória na maioria dos países. O Pisa é realizado pela Organização para Cooperação e Desenvolvimento Econômico (OCDE). Há uma coordenação nacional em cada país participante. No Brasil, esta coordenação cabe ao Inep. O objetivo do Pisa é produzir indicadores que contribuam para a discussão da qualidade da educação nos países participantes, de modo a subsidiar políticas de melhoria do ensino básico. A avaliação procura verificar até que ponto as escolas de cada país participante estão preparando seus jovens para exercer o papel de cidadãos na sociedade contemporânea. A avaliação acontece a cada três anos.
} 
menores de dezoito anos. Isso, porque, os pais delegam às escolas, públicas ou privadas, a educação que é um dever primeiro da família.

Enfim, aspectos como os acima citados tem sido a razão para algumas famílias optarem pela educação domiciliar, cuja abordagem se dará no decorrer do trabalho.

\section{A AUTONOMIA FAMILIAR}

A família nos termos do artigo 226 da Constituição Federal é a base da sociedade e tem especial proteção do Estado (BRASIL, 1988).

O princípio do Planejamento Familiar foi consagrado no texto constitucional, se constituindo como livre decisão do casal na condução do núcleo familiar, com a proibição de qualquer interferência indevida por parte de instituições oficiais ou particulares, cabendo ao Poder Público oportunizar recursos educacionais e científicos para o seu exercício, ao menos é isso que se infere do Art. $226, \$ 7^{\circ}$, da Constituição Federal.

Acerca do tema em questão, o professor Arnaldo Rizzardo assevera o seguinte:

[...] desde que não afetados princípios de direito ou o ordenamento legal, à família reconhece-se a autonomia ou liberdade na sua organização e opções de modo de vida, de trabalho, de subsistência, de formação moral, de credor religioso, de educação dos filhos, de escolha de domicílio, de decisões quanto à conduta e costumes internos. Não se tolera a ingerência de estranhos - quer de pessoas privadas ou do Estado -, para decidir ou impor no modo de vida, nas atividades, no tipo de trabalho e de cultura que decidiu adotar a família. Repugna admitir interferências externas nas posturas, nos hábitos, no trabalho, no modo de ser ou de se portar, desde que não atingidos interesses e direitos de terceiros (2006, p. 15).

O livre planejamento familiar é constantemente ligado com as questões de fecundidade, número de filhos, sobretudo porque a Lei Federal n. 9.263/97 tratou do tema da seguinte forma “Art. $2^{\circ}$ Para fins desta Lei, entende-se planejamento familiar como o conjunto de ações de regulação da fecundidade que garanta direitos iguais de constituição, limitação ou aumento da prole pela mulher, pelo homem ou pelo casal” (BRASIL, 1997).

Em que pese a dicção do legislador ordinário, o princípio do livre planejamento familiar pode ser visto em suas várias facetas, especialmente a intervenção mínima do Estado e de instituição privadas na autonomia familiar, seja quando a família professa sua fé, aspectos culturais e afins, porém o que interessa no presente artigo é seu aspecto educacional. 
Aliás, o homeschooling, em uma dimensão maior, envolve, para seus defensores, um direito de abstenção por parte do Estado, isso muito ligado aos direitos de primeira dimensão de liberdades negativas, como forma de preservar a autonomia privada (grupo familiar).

Até mesmo porque como leciona Alexandre Magno Moreira um dos aspectos da dignidade da pessoa humana é a liberdade de decidir acerca de seus próprios rumos, de manter sua autonomia privada e, dentro desse contexto, se encaixa a própria vida familiar, com possibilidade das escolhas próprias. Algumas intervenções nessa autonomia são necessárias, como nos casos que envolvam a saúde, mas no que se refere às escolas tal necessidade é questionável (2017, p. 88-90).

A Constituição Federal prevê o direito à liberdade quando dispõe no artigo $5^{\circ}$, caput, que: "Todos são iguais perante a lei, sem distinção de qualquer natureza, garantindo-se aos brasileiros e aos estrangeiros residentes no País a inviolabilidade do direito à vida, à liberdade, à igualdade, à segurança e à propriedade, nos termos seguintes”, em seguida, o inciso II afirma: "ninguém será obrigado a fazer ou deixar de fazer alguma coisa senão em virtude de lei” (BRASIL, 1988).

O Código Civil, aliás, se harmoniza com esse entendimento, conforme se pode observar de seu art. 1.513, a saber: "É defeso a qualquer pessoa, de direito público ou privado, interferir na comunhão de vida instituída pela família" (BRASIL, 2015).

No mesmo sentido, o art. 1.634 do mesmo Código Civil dispõe da seguinte forma: “art. 1634: Compete aos pais, quanto à pessoa dos filhos menores: I - dirigir-lhes a criação $e$ educação" (BRASIL, 2015).

Nos termos do art. $4^{\circ}$ da Lei 8.069/1990 (Estatuto da Criança e Adolescente) também cabe à família assegurar, com prioridade absoluta, o direito à educação (BRASIL, 1990). Inclusive, o Constituinte de 1988 em nenhum momento vedou modalidades diversas de educação formal além de estabelecer que a educação não é dever exclusivo do Estado, mas também da família e da sociedade. De tal sorte é importante que a família e a sociedade assumam seus deveres e cotas de responsabilidades pelo melhor para todos.

Para Nardejane Martins Cardoso (2016, p. 22) “a obrigatoriedade de garantia da educação, não pode ser reduzida à escolarização na rede oficial de ensino, pois o texto não traz nenhum requisito quanto ao modo de se realizar essa educação formal”. Ela defende ainda que defende que "O acesso de todos os indivíduos à educação não é incompatível com a liberdade da família em optar por fornecer à criança e ao adolescente a educação domiciliar" (CARDOSO, 2016, p. 52). 


\section{HOMESCHOOLING: UMA ABORDAGEM CONSTITUCIONAL E SUA APLICAÇÃO NA ORDEM JURÍDICA BRASILEIRA}

Dessa forma, o homeschooling viria para privilegiar essa posição da família na formação do indivíduo, sendo que a socialização do estudante poderia se dar de outras formas como cursos extraescolares, atividades físicas e afins.

Além disso, o aumento da convivência familiar pode vir a ser salutar, diante do afeto que envolve as relações familiares, além de em alguns casos representar proveito econômico, pois não envolveria o deslocamento do estudante, flexibilidade de horários e segurança.

Em 2009, importante mudança do ECA reforçou a necessidade de se favorecer a convivência familiar (Lei 12.010 de 03 de agosto de 2009).

Conforme Nardejane Martins Cardoso (2014, p. 78) "A convivência familiar é um direito da criança e adolescente, por ser um pressuposto para um pleno desenvolvimento das capacidades inerentes à personalidade do indivíduo".

De outro norte, a liberdade religiosa é uma das facetas que motivam as famílias a adotarem a sistemática da educação domiciliar e de acordo com a Convenção Americana Sobre Direitos Humanos, artigo 12, item 4, é reconhecida a liberdade de consciência e de religião e "Os pais, e quando for o caso os tutores, têm direito a que seus filhos ou pupilos recebam a educação religiosa e moral que esteja acorde com suas próprias convicções”.

Esse argumento parece ser um pouco frágil, diante da laicidade do estado e da livre escolha da escola particular, contudo alguns pais desejam preservar seus valores religiosos e morais que - na sua visão de mundo - podem estar sendo desrespeitados na escola tradicional.

Nos termos do artigo 19 do Estatuto da Criança e Adolescente é direito da criança e do adolescente ser criado e educado no seio de sua família e, excepcionalmente, em família substituta, assegurada a convivência familiar e comunitária, em ambiente que garanta seu desenvolvimento integral (BRASIL, 1991).

As condições inapropriadas das escolas, a desmotivação dos professores, a precarização de materiais pedagógicos aliado ao aumento da violência e da prática constante de bullying nos ambientes escolares têm motivado família a optarem pela educação domiciliar.

Por derradeiro, independente da maneira como será efetivada a educação formal, escolarizada ou domiciliar, é importante acima de tudo prezar pelo melhor interesse da criança. Além disso, é imprescindível empreender esforços para implementar métodos que conforme Raitz e Zluhan (2014, p. 32) "sustentem um fazer pedagógico que contribua para a construção de um presente mais solidário e de um futuro investido de valores de uma 
sociedade efetivamente mais justa e igualitária, numa ação conjunta de todos os órgãos sociais".

Do mesmo modo, Nardejane Martins Cardoso, embora defenda a importância do reconhecimento da educação domiciliar como uma modalidade alternativa de ensino afirma que "A educação domiciliar e educação escolar são modalidades de ensino diferentes, mas com o mesmo escopo, garantir o acesso à instrução, e que efetivamente, a criança e o adolescente possam aprender".

Desse modo, passamos neste momento a analisar com mais detalhes a educação domiciliar.

\section{HOMESCHOOLING}

O Homescooling em tradução literal pode ser entendido como "educação escolar em casa”, cuja premissa básica é o protagonismo dos pais na educação de sua prole. Alexandre Magno Moreira explica que essa prática se contrapõe a uma educação massificada supostamente aplicável a todas às famílias, privilegiando a autonomia familiar, dando liberdade para o planejamento escolar familiar (2017, p. 61).

Por seu turno, em artigo sobre a temática, Luciane Muniz Ribeiro Barbosa explica que essa prática de estudos em casa, sem frequentar a escola, significa verdadeira problematização acerca da obrigatoriedade do ensino escolar clássico. Aponta, ainda, a autora que essa é uma prática crescente no Brasil, com 2.500 famílias inseridas nesse contexto, além de ser uma prática consagrada ao redor de globo terrestre, com reconhecimento legal em 63 (sessenta e três) países (2016, p. 154).

Aliás, sobre o modelo norte-americano, conhecido comumente como referência no modelo escolar, inclusive com a importação do termo a discussão brasileira, vale trazer o magistério de Nardejane Martins Cardoso:

Apesar da consolidação do sistema escolar, nas décadas de 1970 e 1980, nos Estados Unidos da América, despontou movimento de retorno à educação realizada diretamente pela família. Isso ocorreu, pois parcela da sociedade americana mostrou-se insatisfeita com o ensino escolar, questionou sua qualidade, bem como, alegou objeção de consciência religiosa, pois, para alguns dos pais, a grade escolar não era compatível com a moral religiosa da família (2016). 


\section{HOMESCHOOLING: UMA ABORDAGEM CONSTITUCIONAL E SUA APLICAÇÃO NA ORDEM JURÍDICA BRASILEIRA}

Contudo, tal proposta educacional não é exatamente novidade, aliás, a instrução em casa precede a própria educação formal escolar, conforme ensina Alexandre Magno Moreira, até o Século XIX, a educação se dava em casa, com a contratação de tutores e preletores para a instrução da prole das famílias mais abastadas ou do ofício paterno, nas mais humildes (2017, p. 68).

Tal prática não encontra regulamentação no direito pátrio, ou seja, não está explicitamente vedada ou autorizada pelo ordenamento, entretanto o art. 208, $\S 3^{05}$, da Constituição Federal, fala da frequência escolar, enquanto que o Código Penal classifica como delito de abandono intelectual deixar de promover a instrução primária de filho em idade escolar. ${ }^{6}$

O vácuo legislativo ensejou que alguns casos fossem apreciados pelo Poder Judiciário, com destaque para o Superior Tribunal de Justiça que assim se manifestou:

MANDADO DE SEGURANÇA. ENSINO FUNDAMENTAL. CURRICULO MINISTRADO PELOS PAIS INDEPENDENTE DA FREQUÊNCIA À ESCOLA. IMPOSSIBILIDADE. AUSÊNCIA DE DIREITO LÍQUIDO E CERTO. ILEGALIDADE E/OU ABUSIVIDADE DO ATO IMPUGNADO. INOCORRÊNCIA. LEI 1.533/51, ART. $1^{\circ}$, CF, ARTS. 205 E 208, $\S 3^{\circ}$; LEI 9.394/60, ART. 24, VI E LEI 8.096/90, ARTS. 5, 53 E 129.

1. Direito líquido e certo é o expresso em lei, que se manifesta inconcusso e insuscetível de dúvidas.

2. Inexiste previsão constitucional e legal, como reconhecido pelos impetrantes, que autorizem os pais ministrarem aos filhos as disciplinas do ensino fundamental, no recesso do lar, sem controle do poder público mormente quanto à frequência no estabelecimento de ensino e ao total de horas letivas indispensáveis à aprovação do aluno.

3. Segurança denegada à míngua da existência de direito líquido e certo.

(MS 7.407/DF, Rel. Ministro FRANCISCO PEÇANHA MARTINS, PRIMEIRA SEÇÃO, julgado em 24/04/2002, DJ 21/03/2005, p. 203)

Em contrapartida, Ribeiro Barbosa expõe que uma família paranaense conseguiu autorização judicial, submetida à verificação pelo Poder Público, quanto ao cumprimento dos objetivos constitucionais e legais para com a educação das crianças, para a prática do homescholling. Tal decisão destacou a ideia de que, independentemente dos meios, o que se busca é a melhor aprendizagem possível (2016, p. 157).

\footnotetext{
${ }^{5}$ Art. 208. O dever do Estado com a educação será efetivado mediante a garantia de: [...]

$\$ 3^{\circ}$ Compete ao Poder Público recensear os educandos no ensino fundamental, fazer-lhes a chamada e zelar, junto aos pais ou responsáveis, pela freqüência à escola.

${ }^{6}$ Art. 246 - Deixar, sem justa causa, de prover à instrução primária de filho em idade escolar:

Pena - detenção, de quinze dias a um mês, ou multa.
} 
Mais recentemente, o Tribunal de Justiça do Rio Grande do Sul, na Apelação Cível No 70052218047, com Relatoria do Desembargador Ricardo Moreira Lins Pastl, decidiu em 16/05/2013, pela impossibilidade do homescholling. O acórdão manteve a decisão de primeiro grau, mesmo com os argumentos da impetrante / recorrente de que a frequência escolar foi responsável por lhe causar inúmeros transtornos, dentro os quais o convívio com alunos mais velhos, de sexualidade mais desenvolvida, a existência de hábitos diversos, além de por convicção religiosa discordar de algumas imposições pedagógicas do ensino regular.

Tanto o juiz de primeiro grau quanto os julgadores do Tribunal de Justiça do Rio Grande do Sul entenderam que, nos termos da Constituição, caberia à impetrante frequentar instituições escolares reguladas pelo Poder Público.

Tal acórdão foi objeto de Recurso Extraordinário n. 888.815, tendo o Supremo Tribunal Federal entendido pela Repercussão Geral da questão, cuja relatoria coube ao Ministro Luís Roberto Barroso que enxergou a colisão de princípios constitucionais, merecendo transcrição o segundo ponto: "No caso, discutem-se os limites da liberdade dos pais na escolha dos meios pelos quais irão prover a educação dos filhos, segundo suas convicções pedagógicas, morais, filosóficas, politicas elou religiosas.”, com julgamento de mérito em 12/09/2018, cujo acórdão ainda está pendente de publicação, porém, em síntese, a ausência de previsão legal sobre a matéria, impediria sua prática.

Dentro desse contexto, será iniciado o próximo tópico do presente trabalho visando tratar da ponderação os princípios envolvidos no caso em apreço, bem como que que deveriam ser em eventual legislação sobre a matéria.

\section{COLISÃO ENTRE PRINCÍPIOS}

Nesse tópico será proposta uma forma de resolução acerca da colisão de princípios e normas que regulam o homeschooling, no intuito de chegar a uma solução jurídica razoável e proporcional acerca da constitucionalidade do tema, portanto, em um primeiro momento se discutirá acerca da teoria da colisão de princípios e - na sequência - da técnica da ponderação que pretensamente resolverá o conflito.

José Sérgio da Silva Cristóvam destaca que a colisão entre os princípios constitucionais encontra amparo no campo axiológico, devendo ser observado a situação concreta, diante de suas circunstâncias fáticas e jurídicas, o princípio que preponderará frente ao outro (2016, p. 252). 


\section{HOMESCHOOLING: UMA ABORDAGEM CONSTITUCIONAL E SUA APLICAÇÃO NA ORDEM JURÍDICA BRASILEIRA}

Sobre esse fenômeno, Barroso menciona que diante do pluralismo e a diversidade de valores que caracterizam a Carta Política de 1988, existirá um choque entre princípios, cuja resolução, no caso concreto, uma especificidade desse fenômeno de diversidade de direitos fundamentais (2011, p. 353).

Paulo Bonavides, com fulcro nas teses de Alexy, expõe que a colisão entre princípios antagônicos em um caso concreto não importa em revogação ou nulidade de um deles, apenas um afastamento momentâneo para o outro se sobressair. Em situações específicas um cederá lugar ao outro, a depender da situação fática proposta, tendo carga axiológica diversa em cada caso (2012, p. 289-290).

Infere-se das doutrinas selecionadas que o enfrentamento de princípios não implica na revogação de um deles, mas sim na cessão momentânea de sua eficácia para que outro princípio, de igual hierarquia, prevaleça no caso concreto.

Sobre esse contexto, Cristóvam faz uma apurada diferenciação entre os "casos jurídicos fáceis" nos quais há dois pontos básicos: fato e norma a ser aplicada, ao contrário dos "casos difíceis, em que princípios constitucionais se chocam, ocasião em que é necessário ao intérprete valer-se de uma argumentação jurídica viável a fundamentar à decisão judicial (2016, p. 140).

Essa necessidade de buscar a melhor solução dentro da ordem jurídica para casos que envolvam a confrontação de mais de um bem assegurado constitucionalmente, segundo Ingo Wolfgang Sarlet, fez nascer a técnica ponderação ou balanceamento, dado que o método habitual de subsunção não encontraria resultado satisfatório e lembra que o procedimento de ponderação tem ganho tanto destaque que o festejado Canotilho chega a falar de um "Estado de Ponderação" (2012, p. 210).

Cristóvam adverte que a técnica da ponderação implica na adoção de um modelo racional, com fulcro a otimizar os valores constitucionais, advertindo o que autor que esse sistema, deverá ter observar às balizas constitucionais, além do próprio sistema de defesa dos direitos fundamentais, cuja incidência incidirá tanto na arena política como na jurídica (2016, p. 262-264).

O método da ponderação é usualmente utilizado no Supremo Tribunal Federal e se dá quando dispositivos legais de igual hierarquia que se colidem. $\mathrm{O}$ doutrinador assevera que esse procedimento é escalonado em 3 (três) etapas: a) reconhecimento das normas em confronto, com a divisão entre as normas que fundamentam tal decisão em contraposição com aquelas que a antagonizam; b) o segundo procedimento dessa técnica consiste no exame fático 
e concreto do caso; c) por fim, a terceira etapa trata da investigação conjunta do grupo de normas em análises, com o sopesamento dos argumentos e fatos, tendo a proporcionalidade e razoabilidade como princípios indicadores, a fim de concluir a melhor solução possível (2011, p. 358-359).

Supera essa breve conceituação da técnica da ponderação, passa-se a aplica-la no caso concreto para fins de verificação da constitucionalidade do homescooling, cujos argumentos favoráveis seriam os princípios da liberdade de ensino (art. 206, II, CF) e do pluralismo de ideias e de concepções pedagógicas (art. 206, III,CF), tendo-se presente a autonomia familiar assegurada pela Constituição em contrariedade com

De outro norte, em sentido contrário à aplicação dessa metodologia de ensino, o art. 205, da Carta Política de 1988, fez a procedência do vocábulo "estado" em relação ao termo "família" ao regular as metas da educação, o que indica - ao menos em tese - uma certa prevalência do Estado sobre a família no dever pela educação escolar.

No mesmo contexto, o art. 205, § $3^{\circ}$, também da Constituição Federal estabelece que "Compete ao Poder Público recensear os educandos no ensino fundamental, fazer-lhes a chamada e zelar, junto aos pais ou responsáveis, pela frequência à escola"

Ribeiro Barbosa traz o panorama da legislação infraconstitucional o que ajuda a clarear o debate aqui proposto:

\begin{abstract}
A legislação decorrente da Lei Maior também parece inclinar-se para uma prioridade do Estado na matéria educacional. A Lei de Diretrizes e Bases da Educação Nacional (LDB - Lei $n^{\circ} 9.394 / 96$ ) previu em seu art. $1^{\circ}$ que a educação abrange os processos formativos que se desenvolvem, entre outros espaços, na vida familiar; porém, no $\S$ $1^{\circ}$ há o registro de que a educação escolar deve acontecer, predominantemente, por meio do ensino em instituições próprias. O Estatuto da Criança e do Adolescente (ECA - Lei ${ }^{\circ}$ 8.069/90) também deixa claro, em seu art. 55, que "Os pais ou responsável têm a obrigação de matricular seus filhos ou pupilos na rede regular de ensino", ressaltando esse dever também no art. 129, ao explicitar os deveres dos pais para com a educação: "V - obrigação de matricular o filho ou pupilo e acompanhar sua frequência e aproveitamento escolar" (2016, p. 156).
\end{abstract}

Como se vê, estar-se diante de uma situação em que não há regulação explícita da matéria, havendo normas constitucionais de valor axiológico e a previsão do direito constitucional à educação pública proporcionada pelo estado, sem a exclusão da educação em estabelecimentos privados.

Seguindo na toada da técnica da ponderação, é preciso, como forma de contemplar a segunda fase desse método, analisar a situação fática envolvida, a qual consiste basicamente 


\section{HOMESCHOOLING: UMA ABORDAGEM CONSTITUCIONAL E SUA APLICAÇÃO NA ORDEM JURÍDICA BRASILEIRA}

na possibilidade de uma família proceder a educação de seus filhos em casa, de forma independente da escola.

Esse é um fenômeno que tem ganhado notoriedade no Brasil e aumento de relevo social, sobretudo com o desenho pífio dos alunos em exames internacionais, além da escalada da violência e do caos do transporte público nas grandes cidades brasileiras, o deslocamento dos jovens muitas vezes deixa de ser recomendável.

Importante trazer - ainda - a informação que consta na decisão que admitiu a repercussão geral no Recurso Extraordinário n. 888815/RS que após o reconhecimento pelo MEC da utilização do desempenho no ENEM como certificação de conclusão de ensino médio, em 2012, o número de adeptos do homeschooling no Brasil dobrou e atingiu 2.000 famílias, isso segundo informações da Associação Nacional de Educação Familiar (ANED).

Dessa forma, chega-se à terceira etapa da técnica da ponderação, com o sopesamento das normas jurídicas em conflito e dos fatos. A primeira das conclusões é de que não existe óbice jurídico explícito para a efetivação do homeschooling, podendo o hermeneuta mais apressado acreditar que vigeria o ramo do princípio da legalidade ao particular de que aquilo que não está proibido pelo ordenamento, está autorizado.

Entretanto, o art. 209 da Constituição Federal assim dispõe:

Art. 209. O ensino é livre à iniciativa privada, atendidas as seguintes condições: I - cumprimento das normas gerais da educação nacional; II - autorização e avaliação de qualidade pelo Poder Público.

Ou seja, embora admitida a educação particular, ainda assim é necessário autorização e avaliação da qualidade pelo serviço público. Contudo, diante da não regularização do homescholling estar-se-á diante do princípio da legalidade strict sensu que envolve a Administração Pública.

José Afonso da Silva explica que esse Princípio da Legalidade impõe à administração pública agir conforme aquilo que a lei autoriza, isso porque a atividade administrativa deve sempre perseguir os valores constitucionalmente protegidos (2006, p. 427).

Aliás, a jurisprudência gaúcha já caminhou no mesmo sentido:

AGRAVO INTERNO. ECA. MEDIDA PROTETIVA. MODALIDADE HOMESCHOOLING - EDUCAÇÃO DOMICILIAR. Inexistindo previsão legal de ensino na modalidade domiciliar, não há no caso direito a ser amparado. Decisão mantida, conforme entendimento da Câmara. RECURSO DESPROVIDO. (Agravo 
No 70068377100, Oitava Câmara Cível, Tribunal de Justiça do RS, Relator: Liselena Schifino Robles Ribeiro, Julgado em 09/03/2016).

Assim, tem-se o primeiro aqui o primeiro óbice à educação domiciliar, o que inclusive foi levado em consideração pelo STF no julgamento do RE 888815.

No mais, a escola continua sendo vista como lugar de socialização e como primeiro local de convívio social, conforme abordado em tópico próprio. A diversidade de concepções ideológicas também não seria preservada com a educação em casa. Ora, uma escola, por mais que adote uma linha pedagógica, ainda assim possuí uma pluralidade de professores e mesmo de colegas que ensejarão aos alunos diferentes pontos de vistas sobre o mundo e até sobre si mesmos, aos autores desse artigo parece que convivência com os diferentes é salutar e recomendável.

De outro norte, a proliferação do homescholling significaria a precarização do ensino, cujas deficiências já são conhecidas e diante das possibilidades da Emenda Constitucional n. Constitucional 95, que limita por 20 anos os gastos públicos, poderia se dar um esvaziamento ainda maior da educação pátria.

Dentro desse contexto, na atual ordem jurídica, diante da ausência de regulação, a prática do homeschooling ainda não encontra amparo na ordem jurídica, contudo nada impede que uma futura legislação venha a regular a matéria, cuja constitucionalidade dependeria efetivamente de que a própria educação escolar garantisse meios de socialização do aluno e respeitasse a grade curricular escolar e que esse tipo de educação fosse a exceção, garantindo o Poder Público os investimentos em educação, além de testes regulares para a verificação da qualidade do aprendizado.

\section{CONSIDERAÇÕES FINAIS}

A educação é um direito humano fundamental de crianças e adolescentes e a Constituição Federal assim como a legislação infraconstitucional elegem o Estado, a família e a sociedade como responsáveis por promover as condições necessárias para o aprendizado.

Esse artigo pretendeu ser o mais pluralista e democrático possível na observância dos argumentos contrários e favoráveis ao instituto do homeschooling, trazendo argumento de diversas correntes de pensamento. 


\section{HOMESCHOOLING: UMA ABORDAGEM CONSTITUCIONAL E SUA APLICAÇÃO NA \\ ORDEM JURÍDICA BRASILEIRA}

Embora a educação pelo sistema escola seja a modalidade prevista no ordenamento jurídico brasileiro e não haja regulamentação permitindo os pais de educarem seus filhos em casa, no Brasil, mais de 3 (três) mil famílias passaram a adotar a educação domiciliar.

A grande questão é que o Poder Legislativo brasileiro é letárgico e a ausência de regulamentação da matéria acabou no Poder Judiciário que por autocontenção deixou de apreciar a constitucionalidade do referido instituto, vedando sua prática por ausência de previsão legal, no Recurso Extraordinário n. 888.815, já mencionado no corpo desse artigo.

Dessa forma, em vista do atual estado de arte, diante da técnica da ponderação de princípios, tentou-se dar uma contribuição científica para a discussão, trazendo argumentos que fatalmente serão discutidos em eventual legislação sobre a matéria.

Por fim, a formação educacional, seja escolarizada ou não, deve respeitar acima de tudo o melhor interesse da criança e do adolescente, por isso futura regulamentação da matéria deve vir acompanhada de meios de socialização do estudante e que haja garantia que este tenha acesso a diferentes pontos de vista em sua formação, mesmo que caseira.

\section{REFERÊNCIAS}

BARBOSA, Luciane Muniz Ribeiro. HOMESCHOOLING NO BRASIL: AMPLIAÇÃO DO DIREITO À EDUCAÇÃ̃ OU VIA DE PRIVATIZAÇÃO? Educ. Soc. [online]. 2016, vol.37, n.134, pp.153-168. ISSN 0101-7330. Disponível em: <http://dx.doi.org/10.1590/ES0101-73302016157215>. Acesso em 04 set. 2018.

BONAVIDES, Paulo. Curso de Direito Constitucional. 27 ed. São Paulo: Ed Malheiros Editores LTDA, 2012.

BRASIL. Constituição da República Federativa do Brasil (1988). Disponível em <http://www.planalto.gov.br/ccivil_03/constituicao/ConstituicaoCompilado.htm > . Acesso em 01 set. 2018.

BRASIL. Convenção sobre os Direitos das Crianças de 20 de novembro de 1989 (Decreto $\mathrm{n}^{\circ} \quad 99.710$ de 21 de novembro de 1990). Disponível em: < http://www.planalto.gov.br/ccivil_03/decreto/1990-1994/D99710.htm>. Acesso em: 06 set.2018.

BRASIL. Declaração Universal dos Direitos Humanos. Adotada e proclamada pela resolução 217 A (1ll) da Assembleia Geral das Nações Unidas em 10 de dezembro de 1948. Disponível em: <http://portal.mj.gov.br/sedh/ct/legis_intern/ddh_bib_inter_universal.htm>. Acesso em: 01 set. 2018. 
BRASIL. Lei $\mathbf{n}^{\circ}$ 8.069, de 13 de Julho de 1990. Dispõe sobre o Estatuto da Criança e do Adolescente e dá outras providências. Disponível em: <http://www.planalto.gov.br/ccivil_03/leis/L8069.htm>. Acesso em 02 set. 2018.

BRASIL. Lei $\mathbf{n}^{\circ}$ 9.394, de 20 de Dezembro de 1996. Estabelece as diretrizes e bases da educação nacional (LDB). Disponível em: <http://www.planalto.gov.br/ccivil_03/leis/L9394.htm>. Acesso em 02 set. 2018.

BRASIL. SUPREMO TRIBUNAL FEDERAL - STF. Repercussão Geral no Recurso Extraordinário no 888.815 do Rio Grande do Sul, de 04 de junho de 2015. Disponível em: <http://redir.stf.jus.br/paginadorpub/paginador.jsp?docTP=TP\&docID=8678529>. Acesso em: 03 set. 2018.

BRASIL. SUPERIOR TRIBUNAL DE JUSTIÇA - STJ. Mandado de Segurança no 7.407 de 24 de abril de 2002. Disponível em: $<$ https://ww2.stj.jus.br/processo/revista/inteiroteor/?num_registro=200100228437\&dt_publica cao=21/03/2005>. Acesso em: 05 set. 2018 .

BRASIL. TRIBUNAL DE JUSTIÇA DO RIO GRANDE DO SUL - TJRS. Agravo Interno

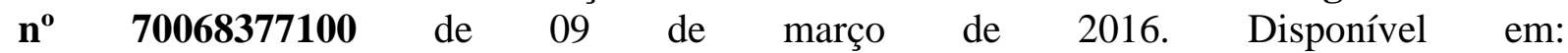
$<$ http://www.tjrs.jus.br/busca/search?q=\&proxystylesheet=tjrs_index\&client=tjrs_index \&filte $\mathrm{r}=0 \&$ getfields $=* \& \mathrm{aba}=$ juris\&entsp $=\mathrm{a} \_$politica-site $\& \mathrm{wc}=200 \& \mathrm{wc} \_\mathrm{mc}=1 \&$ oe $=\mathrm{UTF}-$

$8 \& \mathrm{ie}=\mathrm{UTF}-$

$8 \& \mathrm{ud}=1 \&$ sort=date $\% 3 \mathrm{AD} \% 3 \mathrm{AS} \% 3 \mathrm{Ad} 1 \&$ as_qj=\&site=ementario\&as_epq=\&as_oq=\&as_eq $=\&$ partialfields=n\%3A70068377100\&as_q=+\#main_res_juris $>$. Acesso em 07 set. 2018.

BRASIL. TRIBUNAL DE JUSTIÇA DO RIO GRANDE DO SUL - TJRS. Apelação Cível $\mathbf{n}^{\mathbf{0}} \mathbf{7 0 0 5 2 2 1 8 0 4 7}$ de 16 de maio de 2013. Disponível em: $<$ http://www.tjrs.jus.br/busca/search?q=\&proxystylesheet=tjrs_index\&client=tjrs_index \&filte $\mathrm{r}=0 \&$ getfields $=* \& \mathrm{aba}=$ juris\&entsp $=\mathrm{a} \_$politica-site $\& \mathrm{wc}=200 \& \mathrm{wc} \_\mathrm{mc}=1 \&$ oe $=\mathrm{UTF}-$

$8 \& \mathrm{ie}=\mathrm{UTF}-$

$8 \&$ ud=1\&sort=date $\% 3 \mathrm{AD} \% 3 \mathrm{AS} \% 3 \mathrm{Ad} 1 \&$ as_qj=\&site=ementario\&as_epq=\&as_oq=\&as_eq $=\&$ partialfields=n\%3A70052218047\&as_q=+\#main_res_juris $>$. Acesso em 07 set. 2018.

CARDOSO, Nardejane Martins. O direito de optar pela educação domiciliar no brasil. Dissertação (Mestrado em Direito Constitucional). Universidade da Fortaleza: Fortaleza. 2016. Disponível em <https://uol.unifor.br/oul/conteudosite/F10663420161121150305646221/Dissertacao.pdf>. Acesso em 01 set. 2018.

CRISTÓVAM, José Sérgio da Silva. Princípios Constitucionais: razoabilidade, proporcionalidade e argumentação jurídica. 2 ed. rev. e atual. Curitiba: Juruá Editora, 2016.

FARIAS, Cristiano Chaves de. Manual de Direito Civil. Volume Único / Cristiano Chaves de Farias, Felipe Braga Nett, Nelson Rosenvald - 3. ed. rev. atual. e ampl. - Salvador. Ed. JusPodvm, 2018.

FREIRE, Paulo. Pedagogia do oprimido: saberes necessários à prática educativa. $51^{\mathrm{a}}$ ed Rio de Janeiro; Paz e Terra. 2015. 
INSTITUTO NACIONAL DE ESTUDOS E PESQUISAS EDUCACIONAIS ANÍSIO TEIXEIRA - INEP. Programa Internacional de Avaliação de Estudantes - PISA. Disponível em:

$<$ http://download.inep.gov.br/acoes_internacionais/pisa/resultados/2015/pisa_2015_brazil_prt. pdf>. Acesso em: 06 set. 2018.

MATTOS NETO, Antônio José de. Direitos humanos e democracia inclusiva / Antônio José de Mattos Neto, Homero Lamarão Neto e Raimundo Rodrigues Santana (orgs.). São Paulo: Saraiva, 2012.

MOREIRA, Alexandre Magno Fernandes. O direito à educação domiciliar. Brasília: Editora Monergismo, 2017.

PAULA, Ana Rita de. Princípios Gerais. In RESENDE, Ana Paula Crosara de; VITAL, Flavia Maria de Paiva (orgs.). A Convenção sobre Direitos das Pessoas com Deficiência comentada. Brasília: Secretaria Especial dos Direitos Humanos, 2008. Disponível em < https://pt.scribd.com/doc/306351996/A-Convencao-Sobre-Os-Direitos-Das-Pessoas-ComDeficiencia-Comentada> Acesso em: 10 ago. 2018.

RIZZARDO, Arnaldo. Direito de Família. Rio de Janeiro: Forense, 2006.

ROSA, Marizélia Pegow da; STURZA, Janaína Machado. A educação para pessoas com necessidade educativas especiais no Brasil: reflexos trazidos pela declaração universal dos direitos humanos e pela emenda constitucional 45. In GORCZEVSKI, Clóvis (org.). Direitos Humanos, educação e sociedade. Gráfica UFRGS - Porto Alegre: [s.c.p.], 2009.

SALAMANCA. Declaração de Salamanca, 1994. Disponível em: http://portal.mec.gov.br/seesp/arquivos/pdf/salamanca.pdf. Acesso em: 4 set. 2018.

SARLET, Ingo Wolfgang; MARINONI, Luiz Guilherme; MITIDIERO, Daniel. Curso de direito constitucional. São Paulo: Revista dos Tribunais, 2012.

SILVA, José Afonso da. Curso de direito constitucional. $27^{\mathrm{a}}$ Ed. São Paulo: Malheiro Editores Ltda, 2006.

ZLUHAN, Mara Regina e RAITZ, Tânia Regina. A educação em direitos humanos para amenizar os conflitos no cotidiano das escolas. Rev. Bras. Estud. Pedagog. [online]. 2014, vol.95, n.239, pp.31-54. ISSN 2176-6681. Disponível em <http://dx.doi.org/10.1590/S217666812014000100003>. Acesso em 30 ago. 2018. 